\title{
Effects of supplementation with a calcium-rich marine-derived multi-mineral supplement and short-chain fructo-oligosaccharides on serum lipids in postmenopausal women
}

\author{
Barbara E. Cronin, Philip J. Allsopp, Mary M. Slevin, Pamela J. Magee, M. Barbara E. Livingstone, \\ J. J. Strain and Emeir M. McSorley* \\ School of Biomedical Sciences, Northern Ireland Centre for Food and Health, University of Ulster, Coleraine BT52 1SA, \\ Northern Ireland
}

(Submitted 10 August 2015 - Final revision received 27 October 2015 - Accepted 9 November 2015 - First published online 16 December 2015)

\section{Abstract}

Recent literature suggests that Ca supplements have adverse effects on cardiovascular health. The effects of a Ca-rich supplement administered alone or in combination with short-chain fructo-oligosaccharides (scFOS) on serum lipids in postmenopausal women were examined using secondary data from a 24-month double-blind randomised controlled study. A total of 300 postmenopausal women were randomly assigned to daily supplements of $800 \mathrm{mg}$ of $\mathrm{Ca}$ (2.4 g Aquamin) (Ca), $800 \mathrm{mg}$ of Ca with $3 \mathrm{~g}$ of scFOS (CaFOS) or control (maltodextrin) (MD). A full lipid profile, body composition, blood pressure and a range of cytokines were measured at baseline and after 24 months. Intention-to-treat ANCOVA assessed treatment effects between the groups. A significant time-by-treatment effect was observed for LDL and total cholesterol for the Ca and CaFOS groups, with both groups having lower LDL and total cholesterol concentrations compared with MD after 24 months. The control group had mean $(5.2 \mathrm{mmol} / \mathrm{l})$ total cholesterol concentrations above the normal range $(\leq 5 \mathrm{mmol} / \mathrm{l})$ at $24 \mathrm{months}$, whereas values remained within the normal range in the treatment groups. There was no significant treatment effect on HDL-cholesterol, TAG, body composition, blood pressure or cytokine concentrations at 24 months, with the exception of IL-4, where there was a significant increase in the CaFOS group compared with the placebo. This study demonstrates a lipid-lowering effect of both the Ca-rich supplement alone and the supplement with scFOS. At the 4-year follow-up, there was no significant difference between the groups for reported diagnosed cardiovascular conditions.

\section{Key words: Calcium supplementation: Short-chain fructo-oligosaccharides: Lipids: Postmenopausal women}

Ca supplements are frequently taken for their reported benefits in increasing bone mineral density (BMD) and decreasing the risk of osteoporosis ${ }^{(1,2)}$. In addition to the beneficial effects of increasing $\mathrm{Ca}$ intake on bone health, a substantial evidence base also supports a favourable effect of a high Ca intake from dairy foods on cardiovascular health ${ }^{(3,4)}$, including blood lipid profile ${ }^{(5,6)}$.

One of the first studies to show a beneficial role of Ca supplementation on lipid profile reported a $7 \%$ increase in HDL-cholesterol and a $6 \%$ lowering of LDL-cholesterol in 223 postmenopausal women following supplementation with $1 \mathrm{~g} / \mathrm{d}$ calcium citrate over 1 year $^{(7)}$. Studies have since supported a beneficial role of $\mathrm{Ca}$ supplementation (calcium carbonate) in the reduction of LDL and total cholesterol when administered alone as $2 \mathrm{~g} / \mathrm{d}$ over 6 months ${ }^{(8)}$ or in combination with vitamin D $(1.2 \mathrm{~g} / \mathrm{d} \text { over } 15 \text { weeks; } 1 \mathrm{~g} / \mathrm{d} \text { over } 2 \text { years, respectively })^{(9,10)}$. There are also studies that have reported no effect of supplemental $\mathrm{Ca}$ on the lipid profile of postmenopausal women following $1 \mathrm{~g} / \mathrm{d}$ of calcium carbonate over 5 years $^{(11)}$ or healthy men following 600 or $1200 \mathrm{mg} / \mathrm{d}$ of calcium citrate over 2 years $^{(12)}$. Despite these findings, a recent study by Li et al. ${ }^{(13)}$ reported a rise in total cholesterol concentrations compared with placebo following supplementation with $800 \mathrm{mg} / \mathrm{d}$ calcium carbonate in older women over 2 years.

Results from a recent meta-analysis of forty randomised controlled trials (RCT) showed that Ca supplements (about $1 \mathrm{~g} / \mathrm{d}$ ) may contribute to another cardiovascular risk factor by inducing decreases of 2 and $1 \mathrm{mmHg}$ in systolic blood pressure and diastolic blood pressure, respectively, but the response to supplementation was the strongest in those who had low habitual $\mathrm{Ca}$ intakes ${ }^{(14)}$. Other studies have shown no effect of Ca supplementation in postmenopausal women on body composition $^{(15,16)}$, which is related to blood pressure, or on C-reactive protein (CRP) levels, a pro-inflammatory acute phase reactant ${ }^{(17)}$.

Short-chain fructo-oligosaccharides (scFOS) are a form of prebiotic dietary fibre ${ }^{(18)}$ that cannot be hydrolysed by enzymes in the intestine, and therefore are non-digestible ${ }^{(19)}$.

Abbreviations: Ca, Aquamin; CaFOS, Aquamin with NutraFlora; CRP, C-reactive protein; MD, maltodextrin; scFOS, short-chain fructo-oligosaccharide.

* Corresponding author: E. M. McSorley, email em.mcsorley@ulster.ac.uk 
Several animal studies have demonstrated a role for scFOS in increasing $\mathrm{Ca}$ absorption and facilitating the clearance of lipids from the body ${ }^{(20,21)}$. Human intervention studies have also yielded similar results with increased $\mathrm{Ca}$ absorption from scFOS observed in adolescents ${ }^{(22)}$, adult males ${ }^{(23)}$ and postmenopausal women ${ }^{(24)}$, although the bioavailability of Ca was only enhanced in those who were $>6$ years postmenopausal. Further to these findings, scFOS was found to have favourable effects on the bone health of osteopenic postmenopausal women when administered with $\mathrm{Ca}$. In this study, the degree of bone loss was slowed considerably, suggesting a possible role for $\mathrm{Ca}$ and scFOS in $\mathrm{Ca}$ homoeostasis ${ }^{(25)}$. Thus, scFOS administered with this Ca-rich supplement may be beneficial to the lipid profile and other biological parameters ${ }^{(26)}$.

Recent meta-analyses have suggested that the use of Ca supplements alone or with vitamin D may be associated with an increased risk of myocardial infarction and stroke ${ }^{(27,28)}$; however, the methodology of these meta-analyses has been questioned $^{(29)}$. In contrast, no effects were observed on coronary artery calcification from a high Ca intake from diet and supplements ${ }^{(30)}$, and more recently there was no reported effect on carotid intima-media thickness in women receiving $1.2 \mathrm{~g} / \mathrm{d}$ of calcium carbonate ${ }^{(31)}$.

In light of these inconsistencies in the evidence base, the main aim of the present study was to explore the effects of long-term Ca supplementation (with or without scFOS) on serum lipid concentrations in 300 postmenopausal women using secondary data from a 24-month double-blind randomised controlled study, which was designed to investigate the effects of a Ca-rich marine-derived multi-mineral supplement administered alone or in combination with scFOS on bone health in postmenopausal women. The study also incorporated a 4-year follow-up of these women to assess any long-term effects on cardiovascular health.

\section{Methods}

\section{Study design}

A total of 300 postmenopausal women participated in a doubleblind randomised controlled study, which was undertaken at the University of Ulster and is described elsewhere ${ }^{(25)}$. Women were excluded from the study if they were premenopausal or perimenopausal, had a diagnosis of menopause before the age of 40 years, had osteoporosis or a medical condition or used any medication or dietary supplement that affected bone status. The present study reports on a 24-month double-blind randomised controlled study, which examined the effects of a Ca-rich multi-mineral supplement and scFOS on markers of bone health, BMD and bone turnover. Aquamin is a Ca-rich marinederived multi-mineral supplement that is derived from the Lithothamnion species. NutraFlora, a form of scFOS, was used as a prebiotic fibre, with details of the supplements described elsewhere ${ }^{(25)}$. The present study involved three treatment arms with 100 participants randomly allocated to each treatment group to receive $800 \mathrm{mg} / \mathrm{d}$ of $\mathrm{Ca}(2.4 \mathrm{~g}$ Aquamin) (Ca), $800 \mathrm{mg} / \mathrm{d}$ of $\mathrm{Ca}$ with $3 \mathrm{~g}$ of scFOS ( $3.2 \mathrm{~g}$ NutraFlora) (CaFOS) or a control (9.8 g/d maltodextrin) (MD) (Fig. 1). Habitual dietary Ca intake

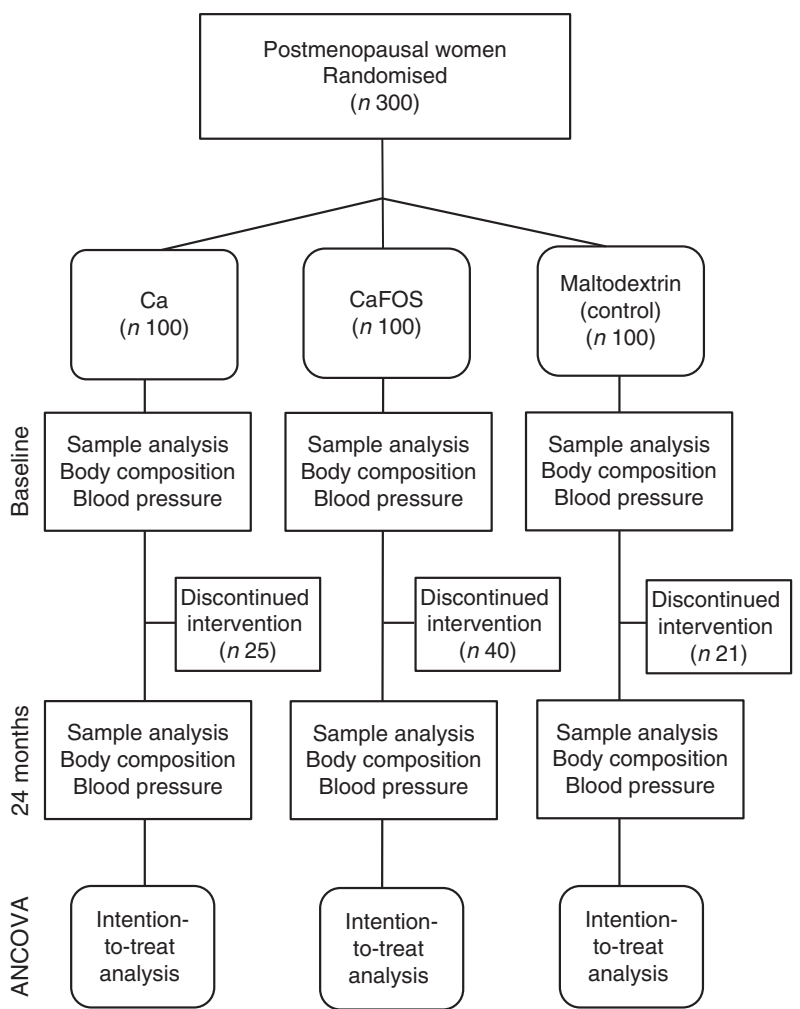

Fig. 1. Study design and analysis of lipids at baseline and after 24 months. $\mathrm{Ca}$, Aquamin; CaFOS, Aquamin and NutraFlora short-chain fructooligosaccharides.

was assessed at baseline using a validated Ca and vitamin D FFQ that was validated against a 14-d dietary history in 120 females using the McCance and Widdowson's the Composition of Foods ${ }^{(32)}$, with findings suggesting that this FFQ may be a more cost-effective method of dietary assessment ${ }^{(33)}$. Compliance (consumption of $\geq 75 \%$ of the supplement provided) was assessed by questionnaire at two time points of the study ${ }^{(25)}$. This study was conducted according to the guidelines laid down in the Declaration of Helsinki, and all procedures involving human subjects were approved by the Research Ethics Committee of the University of Ulster. The original study was registered at www.controlled-trials.com as ISRCTN63118444. Written informed consent was obtained from all the participants.

\section{Measurements}

An overnight fasting blood sample was obtained from each participant at baseline and after 24 months. Weight and height were measured at baseline and after 24 months, and BMI was calculated as weight $(\mathrm{kg}) /$ height $\left(\mathrm{m}^{2}\right)$. Body composition was assessed using a Prodigy DXA system (GE Medical Systems) to provide data on fat mass (FM, kg) and fat-free mass (FFM, kg) obtained by a total body scan. All measures of FM and FFM were adjusted for height to give a fat mass index (FMI, $\mathrm{kg} / \mathrm{m}^{2}$ ) and a fat-free mass index (FFMI, $\mathrm{kg} / \mathrm{m}^{2}$ ) for each participant. Blood pressure was measured at baseline and after 24 months using a blood pressure monitor (Omron 705CP 2; Omron Healthcare). On each occasion, two blood pressure readings 
were taken from the same arm while the participant was seated and at rest with their arm supported at heart level. The mean of the two measurements was calculated for analysis.

\section{Sample analyses}

Serum samples (frozen at $-70^{\circ} \mathrm{C}$ ) were used to measure CRP levels and obtain a full lipid profile: TAG, LDL, HDL and total cholesterol at baseline and after 24 months using an automatic centrifugal clinical chemistry system (iLab 650 Clinical Chemistry System; Instrumentation Laboratory). The Friedewald formula was used to calculate LDL-cholesterol levels. Total cholesterol level was measured in duplicate and an average value was obtained. Adhesion molecules such as intercellular adhesion molecule-1 (ICAM-1) and vascular cell adhesion molecule-1 (VCAM-1) along with IL-6, IL-4, IL-10, TNF- $\alpha$, adiponectin and leptin were measured using multiplex immunoassay ELISA plates and analysed on a Meso-Scale Discovery QuickPlex SQ 120. The intra- and inter-assay CV were $<10$ and $<15 \%$ for all laboratory analyses.

\section{Follow-up questionnaire}

A 4-year post-trial follow-up of the 214 participants who completed the original study ${ }^{(25)}$ was undertaken. A health and lifestyle questionnaire was posted to 211 participants as three were deceased. Of the participants who were deceased, two were from the placebo group and one was from the CaFOS group. Participants were asked whether they had experienced any of the following diagnosed conditions since completing the original study: change in blood pressure, heart attack, stroke, cancer or bone fracture.

\section{Statistical methods}

Statistical analysis was undertaken using SPSS for Windows (version 22.0; SPSS). Variables for lipid profile, body composition, blood pressure and inflammation were assessed for normality and transformed where appropriate for analysis. ANOVA was used to determine differences in baseline characteristics and diagnosed conditions at follow-up ( 4 years after trial) between treatment groups. Intention-to-treat with last observation carried forward ANCOVA (with baseline measures as covariates) was undertaken to assess time-by-treatment effects between groups using least significant difference for post hoc comparisons. Retrospective power was calculated using GPower 3.1.9.2 to determine the minimum sample size required to detect a change in HDLcholesterol levels based on a previous study ${ }^{(7)}$. F test ANCOVA was used with a probability of type 1 error $(0.05)$ and a power of $90 \%$ to yield a total sample size of fifty-nine per group. Statistical significance was set at $P<0 \cdot 05$.

\section{Results}

Baseline characteristics of the study population, by treatment group, are described in Table 1 . Of the 300 study participants, a total of $214(71.3 \%)$ completed the study, of which seventy-five, sixty and seventy-nine individuals had been assigned to the $\mathrm{Ca}$, CaFOS and MD groups, respectively. Digestive problems resulted in a higher dropout rate in the CaFOS group. The mean age of the participants at baseline was 61 (SD 6.4) years, and the women were on average $12 \cdot 6$ (SD 7.6) years postmenopausal. The mean BMI of the participants was 27.4 (SD 4.8$) \mathrm{kg} / \mathrm{m}^{2}$, and the daily total dietary Ca intake from an FFQ was 0.9 (sD 0.4 ) g. Supplementation increased serum Ca concentrations in the $\mathrm{Ca}$ and CaFOS groups by 5 and $6 \%$, respectively, at 24 months, but this was not statistically significant $(P=0 \cdot 06)$. There was a significant difference at baseline for alcohol use $(P=0.03)$ and concentrations of IL-4 $(P=0 \cdot 02)$, which was controlled for in all subsequent analyses. In addition, baseline age, habitual dietary Ca intake and BMI were controlled for in the ANCOVA analysis.

\section{Lipid measurements}

A significant time-by-treatment effect was observed for LDL for the $\mathrm{Ca}(P=0.02)$ and the CaFOS groups $(P<0.01)$, with both groups having lower LDL concentrations compared with MD after 24 months (Fig. 2(a)). A significant treatment effect was also observed for total cholesterol for the $\mathrm{Ca}(P=0.02)$ and the CaFOS $(P<0 \cdot 01)$ groups, with both groups having lower total cholesterol concentrations compared with MD after 24 months (Fig. 2(b)). There was no significant difference in the changeover time between the groups for HDL-cholesterol, TAG or the LDL:HDL ratio. In comparison with intention-to-treat analysis, per-protocol analysis ( $n$ 213) revealed a similar treatment effect of CaFOS on LDL-cholesterol $(P=0.01)$, but this was not observed in the Ca group $(P=0 \cdot 06)$. Although concentrations of both LDL and total cholesterol were maintained within the normal range in the treatment groups, the effects of supplementation with the Ca-rich supplement administered alone or with scFOS on total cholesterol concentrations were no longer statistically significant at 24 months $(P=0.06)$.

\section{Other measurements}

There were no significant treatment effects between the Ca and the CaFOS groups in comparison with MD for body weight, BMI $\left(\mathrm{kg} / \mathrm{m}^{2}\right)$, FMI $\left(\mathrm{kg} / \mathrm{m}^{2}\right)$ or for FFMI $\left(\mathrm{kg} / \mathrm{m}^{2}\right)$ (Table 2). There was no significant treatment effect for systolic $(P=0.33)$ or diastolic $(P=0.80)$ blood pressure for the $\mathrm{Ca}$ and the CaFOS groups when compared with MD, with blood pressure levels above 120/80 $\mathrm{mmHg}$ but below the hypertensive level of $140 / 90 \mathrm{mmHg}$ at baseline and 24 months. There was no significant treatment effect observed for ICAM-1, VCAM-1 or the inflammatory cytokines CRP, IL- 6 , IL-10, TNF- $\alpha$, adiponectin and leptin. A significant treatment effect was observed for IL-4 in the CaFOS group $(P<0.001)$ after 24 months with higher concentrations in the CaFOS group compared with MD (Fig. 3).

\section{Follow-up questionnaire}

In the 4-year post-trial follow-up, a total of 158 participants completed the health and lifestyle questionnaire, yielding a response rate of $75 \%$. Reasons for non-response were as follows: participants were unable to be contacted by phone ( $n$ 29); 
Table 1. Baseline characteristics of participants within the treatment groups: Aquamin (Ca), Aquamin and NutraFlora short-chain fructo-oligosaccharides (CaFOS) and maltodextrin (MD)

(Mean values and standard deviations; percentages; $n$ 100)

\begin{tabular}{|c|c|c|c|c|c|c|c|}
\hline \multirow[b]{2}{*}{ Variables } & \multicolumn{2}{|c|}{$\mathrm{Ca}$} & \multicolumn{2}{|c|}{ CaFOS } & \multicolumn{2}{|c|}{ MD } & \multirow[b]{2}{*}{$P^{*}$} \\
\hline & Mean & SD & Mean & SD & Mean & SD & \\
\hline Age (years) & $61 \cdot 3$ & $6 \cdot 61$ & $61 \cdot 3$ & $6 \cdot 4$ & $60 \cdot 4$ & $6 \cdot 3$ & 0.53 \\
\hline Years since menopause & $13 \cdot 1$ & $8 \cdot 1$ & $12 \cdot 0$ & $7 \cdot 2$ & $12 \cdot 6$ & 7.5 & 0.58 \\
\hline Weight (kg) & 69.9 & $11 \cdot 8$ & $72 \cdot 3$ & 13.5 & $70 \cdot 2$ & $12 \cdot 9$ & 0.28 \\
\hline BMI $\left(\mathrm{kg} / \mathrm{m}^{2}\right)$ & $26 \cdot 8$ & 4.4 & $28 \cdot 0$ & $5 \cdot 2$ & $27 \cdot 3$ & $4 \cdot 8$ & 0.21 \\
\hline Fat mass $(\mathrm{kg})$ & $28 \cdot 0$ & 8.4 & $30 \cdot 3$ & $9 \cdot 6$ & 28.5 & $9 \cdot 2$ & 0.17 \\
\hline Fat-free mass $(\mathrm{kg})$ & $41 \cdot 2$ & $4 \cdot 3$ & 41.5 & $5 \cdot 2$ & $41 \cdot 1$ & $5 \cdot 2$ & 0.85 \\
\hline FMl $\left(\mathrm{kg} / \mathrm{m}^{2}\right)$ & $10 \cdot 8$ & 3.3 & 11.8 & 3.7 & 11.1 & 3.6 & 0.16 \\
\hline FFMI $\left(\mathrm{kg} / \mathrm{m}^{2}\right)$ & $15 \cdot 9$ & 1.4 & $16 \cdot 1$ & 1.8 & $15 \cdot 9$ & 1.6 & 0.72 \\
\hline Alcohol use (\%) & \multirow{2}{*}{\multicolumn{2}{|c|}{$\begin{array}{r}65 \\
5\end{array}$}} & \multicolumn{2}{|c|}{55} & \multicolumn{2}{|c|}{73} & 0.03 \\
\hline Current smoker (\%) & & & & & & & 0.47 \\
\hline Daily total Ca intake from FFQ (g) & 0.9 & 0.4 & 0.9 & 0.4 & 0.9 & 0.4 & 0.68 \\
\hline Systolic blood pressure $(\mathrm{mmHg})$ & 135.4 & 21.6 & $137 \cdot 2$ & $20 \cdot 9$ & $132 \cdot 2$ & $18 \cdot 7$ & 0.13 \\
\hline Diastolic blood pressure $(\mathrm{mmHg})$ & $85 \cdot 0$ & $10 \cdot 8$ & $86 \cdot 3$ & $12 \cdot 8$ & 85.5 & $14 \cdot 1$ & 0.53 \\
\hline Total cholesterol $(\mathrm{mmol} / \mathrm{l})$ & $4 \cdot 8$ & 1.4 & 4.4 & $1.4 \dagger$ & 4.8 & 1.3 & 0.06 \\
\hline LDL-cholesterol (mmol/l) & $2 \cdot 9$ & 1.1 & 2.6 & $1.0 \dagger$ & $2 \cdot 8$ & 0.9 & 0.08 \\
\hline HDL-cholesterol ( $\mathrm{mmol} / \mathrm{l})$ & 1.4 & 0.5 & $1 \cdot 4$ & $0.4 \dagger$ & 1.5 & 0.5 & 0.36 \\
\hline TAG $(\mathrm{mmol} / \mathrm{l})$ & $1 \cdot 1$ & 0.6 & 1.0 & $0.5 \dagger$ & 1.1 & 0.6 & 0.35 \\
\hline LDL:HDL-cholesterol ratio $(\mathrm{mmol} / \mathrm{l})$ & $2 \cdot 0$ & 0.7 & $2 \cdot 1$ & $0.8 \dagger$ & $2 \cdot 1$ & 0.7 & 0.54 \\
\hline $\operatorname{CRP}(\mathrm{mg} / \mathrm{l})$ & 1.96 & 2.02 & 2.55 & 3.49 & $2 \cdot 51$ & 4.81 & 0.44 \\
\hline ICAM-1 (ng/ml)‡ & $389 \cdot 2$ & $180 \cdot 8$ & 407.9 & 163.4 & $346 \cdot 4$ & 141.9 & 0.08 \\
\hline VCAM-1 (ng/ml)§ & $582 \cdot 8$ & 232.5 & $642 \cdot 7$ & $247 \cdot 4$ & 581.4 & $249 \cdot 0$ & 0.21 \\
\hline IL-6 (pg/ml)§ & 0.82 & 0.53 & 0.98 & 0.76 & 0.88 & 0.65 & 0.32 \\
\hline IL-4 (pg/ml)§ & 0.04 & 0.05 & 0.04 & 0.04 & 0.03 & 0.03 & 0.02 \\
\hline $\mathrm{IL}-10(\mathrm{pg} / \mathrm{ml}) \S$ & 0.44 & 0.65 & 0.32 & 0.21 & 0.36 & 0.38 & 0.26 \\
\hline TNF- $\alpha(\mathrm{pg} / \mathrm{ml}) \|$ & 2.06 & 0.63 & $2 \cdot 18$ & 0.59 & 2.09 & 0.61 & 0.33 \\
\hline Adiponectin $(\mu \mathrm{g} / \mathrm{ml}) \|$ & $27 \cdot 9$ & 13.9 & 23.7 & $12 \cdot 9$ & $27 \cdot 1$ & 11.9 & 0.07 \\
\hline Leptin $(\mathrm{ng} / \mathrm{ml}) \boldsymbol{\uparrow}$ & $26 \cdot 2$ & $21 \cdot 8$ & $32 \cdot 4$ & $26 \cdot 4$ & $25 \cdot 1$ & $23 \cdot 1$ & 0.14 \\
\hline
\end{tabular}

FMI, fat mass index; FFMI, fat-free mass index; CRP, C-reactive protein; ICAM-1, intercellular adhesion molecule-1; VCAM-1, vascular cell adhesion molecule-1.

* $P$ values calculated by ANOVA ( $\chi^{2}$ analysis used for alcohol use and smoking).

$\dagger n 99$.

$\ddagger n 219$

$\S n 222$

$\| n 224$.

I $n 221$

there was no response to messages left by phone regarding the follow-up ( $n$ 22); and participants were no longer residing at the same address ( $n$ 2) (letters were returned to the University). Since completing the original study, the majority of participants ( $87 \%$ ) reported to be in good health, $30 \%$ were taking a dietary supplement and 9\% reported taking a daily Ca supplement. Between the responding $\mathrm{Ca}(n$ 55), CaFOS $(n$ 48) and MD ( $n$ 55) groups, there was no significant difference in each of the diagnosed conditions assessed: change in blood pressure, heart attack, stroke, cancer or bone fracture.

\section{Discussion}

In the present study, supplementation with a Ca-rich supplement, administered alone or with scFOS had a significant treatment effect on LDL and total cholesterol concentrations, which were lower than the control group after the 2 years of supplementation. In both groups, LDL and total cholesterol concentrations were maintained within the normal range, whereas in the control group mean concentration of total cholesterol $(5.2$ (SD 1.3) $\mathrm{mmol} / \mathrm{l})$ was above the normal range after 24 months. The sample size used was powered to achieve a significant treatment effect, compliance was assessed with no significant differences in compliance between the treatment groups $^{(25)}$ and intention-to-treat analysis was undertaken.

The results of the present study are in line with other studies that have also demonstrated a favourable effect of Ca-containing supplements on lipid profile using $2 \mathrm{~g} / \mathrm{d}$ of Ca over 6 months $\left(n\right.$ 92) ${ }^{(8)}$ and with a lower dose of $600 \mathrm{mg} / \mathrm{d}$ of Ca with $5 \mu \mathrm{g}$ of vitamin D over 15 weeks $(n 63)^{(9)}$. In contrast, other studies have found no effect on the lipid profile following Ca supplementation, where a dose of either $600 \mathrm{mg} / \mathrm{d}$ or $1.2 \mathrm{~g} / \mathrm{d}$ of $\mathrm{Ca}$ was administered to healthy men over 2 years, suggesting that the effects of Ca supplementation on the lipid profile may be less pronounced in men $(n 323)^{(12)}$. Even with a dose of $1 \mathrm{~g} / \mathrm{d}$ with $10 \mu \mathrm{g}$ of vitamin D over 5 years, Rajpathak et al. ${ }^{(11)} \mathrm{did}$ not observe changes in the lipid status of postmenopausal women ( $n$ 1191), but reported that such findings may be owing to lack of compliance or the effects of $\mathrm{Ca}$ being counteracted by vitamin $\mathrm{D}$, and thereby increasing concentrations of LDLcholesterol and lowering concentrations of HDL-cholesterol ${ }^{(34)}$.

The effects of the Ca-rich supplement on LDL and total cholesterol observed in this study may be due to reduced absorption of fat in the gut. This reduced absorption may be brought about through the formation of fatty soaps composed 

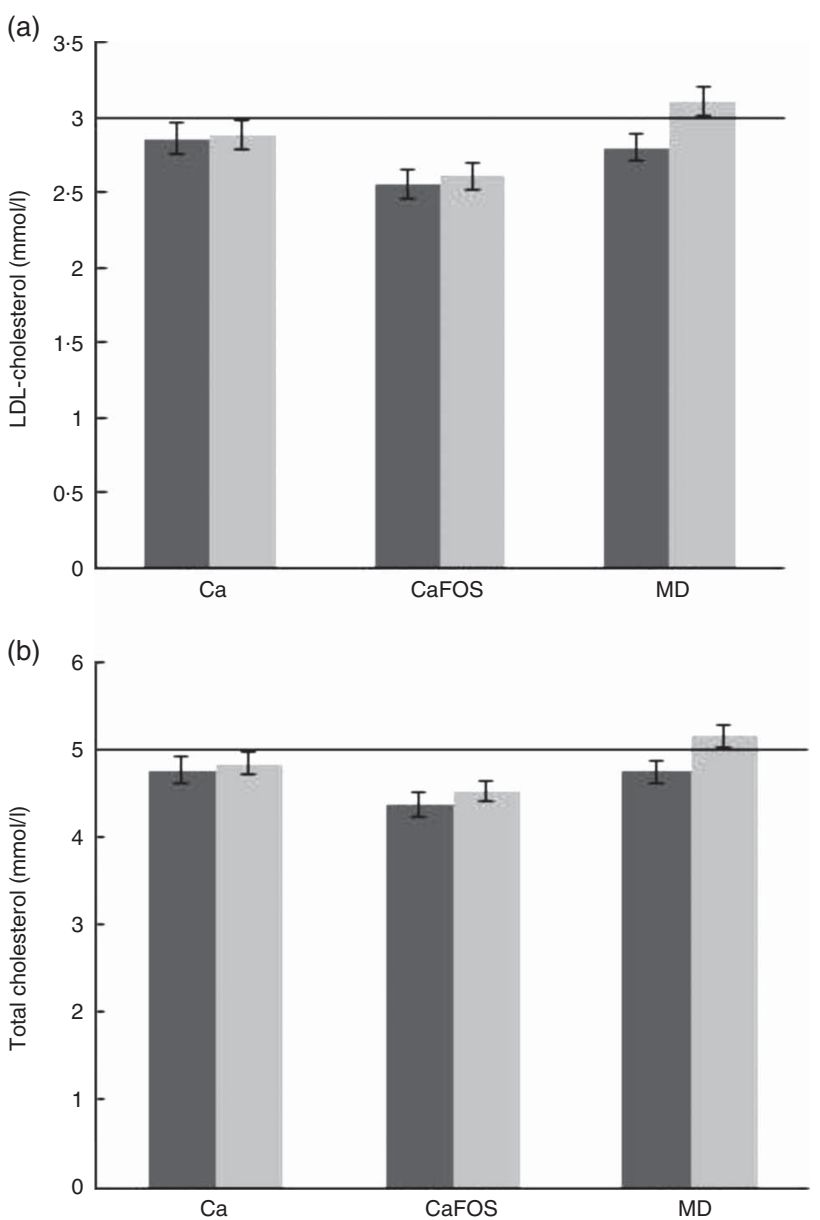

Fig. 2. Effect of Aquamin (Ca), Aquamin and NutraFlora short-chain fructooligosaccharides (CaFOS) and maltodextrin (MD) on LDL and total cholesterol concentrations. Values are means ( $n 100$ in the Ca group, $n 99$ in the CaFOS group and $n 100$ in the MD group), with standard errors represented by vertical bars. (a) ANCOVA (with baseline measures as covariates) and least significant difference (LSD) showed a significant treatment effect in the $\mathrm{Ca}(P=0.02)$ and CaFOS groups $(P<0.01)$ on LDL-cholesterol over 24 months with reference line to show healthy LDL-cholesterol levels $\leq 3 \mathrm{mmol} / \mathrm{l}$. (b) ANCOVA (with baseline measures as covariates) and LSD showed a significant treatment effect in the $\mathrm{Ca}(P=0.02)$ and CaFOS groups $(P<0.01)$ on total cholesterol over 24 months with reference line to show healthy total cholesterol levels $\leq 5 \mathrm{mmol} / \mathrm{l}$. $\square$, Baseline; $\square, 24$ months.

of hydrophobic particles such as cholesterol ${ }^{(5)}$, which are subsequently eliminated in the faeces ${ }^{(8,35,36)}$. An alternative mechanism has been proposed for the lipid-lowering effects of $\mathrm{Ca}$, whereby the binding of $\mathrm{Ca}$ to bile acids stimulates the excretion of secondary bile acids ${ }^{(7,37,38)}$. Depletion of bile acids in the liver stimulates the restoration of bile acids from cholesterol $^{(6)}$, and therefore lowering concentrations of LDL and total cholesterol. This mechanism may also contribute to the results of the present study where the supplement used, Aquamin, not only composed of Ca but also contained additional trace minerals. Thus, the effects of supplementation observed may not be assigned solely to increased Ca alone.

Aside from lipids, Ca supplementation has been proposed to be an effective means of lowering blood pressure with $1.5 \mathrm{~g} / \mathrm{d}$ shown to reduce systolic blood pressure in medicated hypertensive women ( $n$ 34), although no beneficial effect was reported in normotensive individuals $(n 81)^{(39)}$. A meta-analysis of RCT of hypertensive and normotensive individuals reported a small significant reduction in both systolic $(1.09 \mathrm{mmHg})$ and diastolic $(0.87 \mathrm{mmHg})$ blood pressure, which is indicative of a protective cardiovascular effect ${ }^{(40)}$. However, in the present study, there was no significant effect on blood pressure in normotensive individuals.

Similar to the present study, Manios et al. ${ }^{(16)}$ reported no significant effects on body composition following $1.2 \mathrm{~g} / \mathrm{d}$ of Ca supplementation in postmenopausal women $(n$ 101) over a year, but contended that dietary $\mathrm{Ca}$ intake, but not supplemental Ca, may have a favourable effect on body composition findings that are supported by Huang et al. ${ }^{(41)}$ who examined this in Chinese women ( $n$ 4279). Despite these findings, one study - the Women's Health Initiative - reported that $1 \mathrm{~g} / \mathrm{d}$ of Ca administered with $10 \mu \mathrm{g}$ of vitamin D aided the prevention of weight gain in 36282 postmenopausal women, although this was predominantly in those who had inadequate Ca intakes ${ }^{(42)}$. In the present study, no effect on body composition was observed and this may be due to the postmenopausal women in this study having adequate intakes of $\mathrm{Ca}$ - results which are similar to that of Reid et al. ${ }^{(12)}$ who found no effect of supplemental Ca on body composition or blood pressure in healthy men. A potential limitation of the present study is that the groups were not balanced at baseline for the outcomes of the study. To prevent any impact on the statistical findings, baseline values of variables were controlled for in the ANCOVA analysis.

Administration of $3 \mathrm{~g}$ of scFOS along with $800 \mathrm{mg} / \mathrm{d}$ of $\mathrm{Ca}$ as part of the multi-mineral supplement was found to up-regulate the expression of the anti-inflammatory cytokine IL- 4 in postmenopausal women and may impede the development of a pro-inflammatory response, particularly through its inhibitory action on TNF- $\alpha^{(43)}$. No pro-inflammatory effect was observed in any of the treatment groups for the following cytokines CRP, IL-6, IL-10, TNF- $\alpha$, adiponectin and leptin - suggesting that supplementation with this Ca-rich supplement alone or with scFOS does not adversely affect systemic inflammation in this group. The effect of $\mathrm{Ca}$ supplementation on cytokine concentrations remains to be fully elucidated, but to date there is no reported effect of $\mathrm{Ca}$ on circulating CRP concentrations in healthy postmenopausal women ( $n$ 116) following supplementation with $1 \mathrm{~g} / \mathrm{d}$ of Ca over 12 months $^{(17)}$ or on circulating CRP, IL-6 and TNF- $\alpha$ concentrations in postmenopausal women ( $n$ 39) following supplementation with $1 \mathrm{~g} / \mathrm{d}$ of Ca combined with vitamin D over 12 weeks ${ }^{(44)}$. It is suggested that $\mathrm{Ca}$ supplementation increases CVD risk ${ }^{(27)}$; however, the present study reports no effect of this Ca-rich supplement on inflammation or blood pressure, both of which are recognised as risk factors of CVD.

In the present study, there was no significant difference between the reported diagnosed vascular conditions between treatment groups based on a 4-year follow-up, and these findings are in line with a meta-analysis conducted by Wang et al. $^{(45)}$, who reported no associations between Ca supplements administered alone or with vitamin D and CVD risk. Previously, a large-scale, prospective cohort study conducted in 
Table 2. Effects of Aquamin (Ca), Aquamin and NutraFlora short-chain fructo-oligosaccharides (CaFOS) and maltodextrin (MD) on body composition, blood pressure and inflammatory markers in postmenopausal women ( $n 300)$ at 24 months

(Mean values and standard deviations; percentages)

\begin{tabular}{|c|c|c|c|c|c|c|c|}
\hline & \multicolumn{2}{|c|}{$\mathrm{Ca}$} & \multicolumn{2}{|c|}{ CaFOS } & \multicolumn{2}{|c|}{ MD } & \multirow[b]{2}{*}{$P^{*}$} \\
\hline & Mean & SD & Mean & SD & Mean & SD & \\
\hline \multicolumn{8}{|l|}{ Weight (kg) } \\
\hline Baseline & $69 \cdot 6$ & 11.8 & $72 \cdot 3$ & 13.5 & $70 \cdot 2$ & $12 \cdot 9$ & \\
\hline 24 months & $70 \cdot 3$ & $12 \cdot 4$ & $72 \cdot 6$ & $13 \cdot 9$ & $70 \cdot 7$ & $13 \cdot 1$ & 0.63 \\
\hline \multicolumn{8}{|l|}{ BMI $\left(\mathrm{kg} / \mathrm{m}^{2}\right)$} \\
\hline Baseline & $26 \cdot 8$ & 4.4 & 28.0 & $5 \cdot 2$ & $27 \cdot 3$ & $4 \cdot 8$ & \\
\hline 24 months & $27 \cdot 1$ & 4.6 & $28 \cdot 1$ & $5 \cdot 3$ & 27.5 & 4.9 & 0.60 \\
\hline \multicolumn{8}{|l|}{ FMI $\left(\mathrm{kg} / \mathrm{m}^{2}\right)$} \\
\hline Baseline & $10 \cdot 8$ & $3 \cdot 3$ & 11.8 & $3 \cdot 7$ & $11 \cdot 1$ & 3.6 & \\
\hline \multirow{2}{*}{\multicolumn{8}{|c|}{ FFMI $\left(\mathrm{kg} / \mathrm{m}^{2}\right)$}} \\
\hline & & & & & & & \\
\hline Baseline & $15 \cdot 9$ & 1.4 & $16 \cdot 1$ & $1 \cdot 8$ & $15 \cdot 9$ & 1.6 & \\
\hline 24 months & $15 \cdot 8$ & 1.4 & $16 \cdot 0$ & 1.8 & $15 \cdot 8$ & 1.7 & 0.43 \\
\hline \multicolumn{8}{|l|}{$\mathrm{SBP}(\mathrm{mmHg}) \dagger$} \\
\hline Baseline & 135.4 & $21 \cdot 6$ & $137 \cdot 2$ & $20 \cdot 9$ & 131.3 & $16 \cdot 4$ & \\
\hline 24 months & 133.3 & $26 \cdot 8$ & $136 \cdot 8$ & $21 \cdot 7$ & 133.7 & $19 \cdot 4$ & 0.32 \\
\hline \multicolumn{8}{|l|}{$\mathrm{DBP}(\mathrm{mmHg}) \dagger$} \\
\hline Baseline & $85 \cdot 0$ & $10 \cdot 8$ & $86 \cdot 3$ & $12 \cdot 8$ & $84 \cdot 6$ & $10 \cdot 6$ & \\
\hline 24 months & $82 \cdot 6$ & $11 \cdot 2$ & $83 \cdot 1$ & $12 \cdot 2$ & 83.2 & $11 \cdot 2$ & 0.55 \\
\hline \multicolumn{8}{|l|}{ CRP (mg/l) } \\
\hline Baseline & 1.96 & $2 \cdot 02$ & $2 \cdot 55$ & 3.49 & $2 \cdot 51$ & $4 \cdot 81$ & \\
\hline 24 months & 3.00 & $5 \cdot 61$ & 2.93 & 4.44 & $3 \cdot 12$ & 6.01 & 0.34 \\
\hline \multicolumn{8}{|c|}{ ICAM-1 $(\mathrm{ng} / \mathrm{ml}) \ddagger$} \\
\hline Baseline & 389.2 & $180 \cdot 8$ & 407.9 & 163.4 & 346.4 & 141.9 & \\
\hline 24 months & 395.5 & $150 \cdot 8$ & $413 \cdot 7$ & $167 \cdot 0$ & 368.6 & $147 \cdot 2$ & 0.92 \\
\hline \multicolumn{8}{|c|}{ VCAM-1 $(\mathrm{ng} / \mathrm{ml}) \S$} \\
\hline Baseline & 582.8 & 232.5 & $642 \cdot 7$ & 247.4 & 581.4 & 249.0 & \\
\hline 24 months & 585.8 & 204.0 & 654.5 & 256.8 & 589.4 & $250 \cdot 1$ & 0.51 \\
\hline \multicolumn{8}{|l|}{ IL-6 (pg/ml)§ } \\
\hline Baseline & 0.82 & 0.53 & 0.98 & 0.76 & 0.88 & 0.65 & \\
\hline 24 months & 0.94 & 0.94 & 1.04 & 0.75 & 0.90 & 0.65 & 0.51 \\
\hline \multicolumn{8}{|l|}{ IL-10 (pg/ml)§ } \\
\hline Baseline & 0.44 & 0.65 & 0.32 & 0.21 & 0.36 & 0.38 & \\
\hline 24 months & 0.49 & 0.70 & 0.36 & 0.41 & 0.55 & 1.48 & 0.33 \\
\hline \multicolumn{8}{|l|}{ TNF- $\alpha$ (pg/ml)\| } \\
\hline Baseline & 2.06 & 0.63 & $2 \cdot 18$ & 0.59 & 2.09 & 0.61 & \\
\hline 24 months & $2 \cdot 16$ & 0.63 & $2 \cdot 27$ & 0.95 & $2 \cdot 22$ & 0.62 & 0.40 \\
\hline \multicolumn{8}{|c|}{ Adiponectin $(\mu \mathrm{g} / \mathrm{ml}) \|$} \\
\hline Baseline & $27 \cdot 9$ & 13.9 & $23 \cdot 7$ & $12 \cdot 9$ & $27 \cdot 1$ & 11.9 & \\
\hline 24 months & $26 \cdot 7$ & $12 \cdot 4$ & 23.6 & 13.1 & $27 \cdot 3$ & 11.9 & 0.33 \\
\hline \multicolumn{8}{|l|}{ Leptin (ng/ml)ף } \\
\hline Baseline & $26 \cdot 2$ & 21.8 & $32 \cdot 4$ & $26 \cdot 4$ & $25 \cdot 1$ & $23 \cdot 1$ & \\
\hline 24 months & $27 \cdot 2$ & $23 \cdot 8$ & 33.0 & $27 \cdot 3$ & $26 \cdot 1$ & $23 \cdot 8$ & 0.97 \\
\hline
\end{tabular}

FMI, fat mass index; FFMI, fat-free mass index; SBP, systolic blood pressure; DBP, diastolic blood pressure; CRP, C-reactive protein; ICAM-1, intercellular adhesion molecule-1; VCAM-1, vascular cell adhesion molecule-1.

${ }^{*} P$ values calculated by ANCOVA (controlling for baseline age, BMI and habitual dietary Ca intake).

$\dagger n 299$.

$\ddagger n 219$.

$\S n 222$.

II $n 224$.

I $n 221$.

women ( $n$ 74245) reported inverse associations between Ca supplement use $(>1 \mathrm{~g} / \mathrm{d})$ and the risk of a cardiovascular event $^{(46)}$. These findings were corroborated by the Calcium Intake Fracture Outcome Study where $1.2 \mathrm{~g} / \mathrm{d}$ of $\mathrm{Ca}$ did not increase carotid atherosclerosis in women ( $n$ 1103), but it was reported that a high total $\mathrm{Ca}$ intake may reduce this surrogate cardiovascular risk factor ${ }^{(31)}$. In this same cohort, vascular outcomes were assessed over the 5 years of the RCT with a 4.5-year follow-up and reported that $\mathrm{Ca}$ supplementation did not increase the risk of atherosclerotic CVD compared with those receiving placebo ${ }^{(47)}$. A limitation of the present study is that vascular conditions were assessed by a self-reported questionnaire. It has been previously emphasised that care must be taken when using self-reported diagnoses for myocardial infarction and stroke ${ }^{(48)}$, particularly in trials of $\mathrm{Ca}$ supplementation $^{(49)}$.

Further research is warranted to investigate the long-term effects of Ca supplementation on other biological parameters such as clotting factors. In addition, potential effects of $\mathrm{Ca}$ supplementation combined with vitamin $\mathrm{D}$ require investigation 


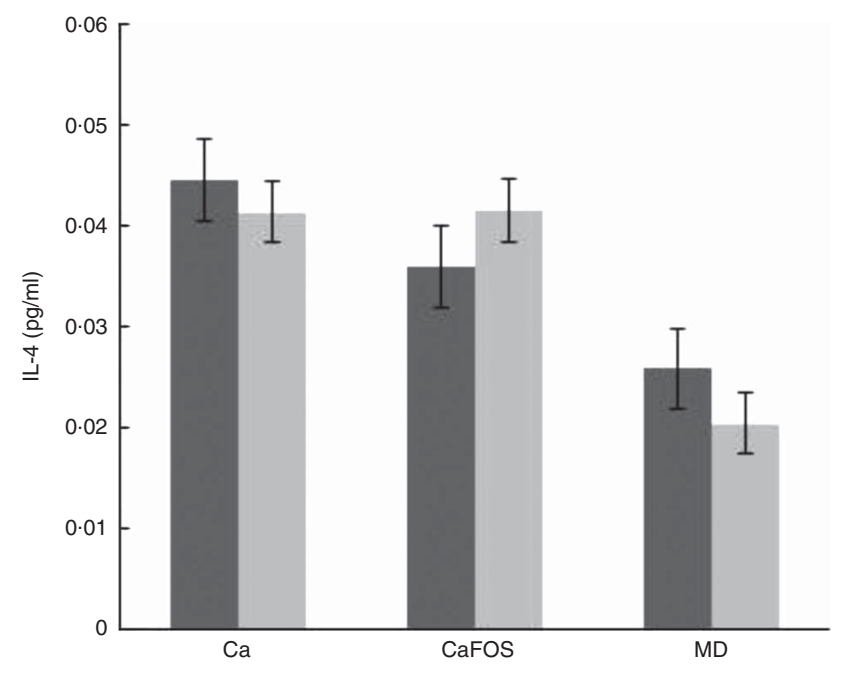

Fig. 3. Effect of Aquamin (Ca), Aquamin and NutraFlora short-chain fructooligosaccharides (CaFOS) and maltodextrin (MD) on IL-4. Values are means ( $n 73$ in the Ca group, $n 78$ in the CaFOS group and $n 71$ in the MD group), with standard errors represented by vertical bars. ANCOVA (with baseline measures as covariates) and least significant difference showed a significant treatment effect for the CaFOS group on IL-4 $(P<0.001)$ over 24 months. $\square$, Baseline; $\square$, 24 months.

owing to the down-regulatory action of Ca on vitamin D, which may subsequently stimulate lipolysis ${ }^{(36)}$.

\section{Conclusion}

Supplementation with a Ca-rich marine-derived multi-mineral supplement alone or with scFOS lowered LDL and total cholesterol concentrations in postmenopausal women over 24 months. Supplementation of Ca with scFOS may up-regulate the expression of the anti-inflammatory cytokine IL-4, thereby suppressing an inflammatory response.

\section{Acknowledgements}

This work was supported by Marigot (Cork, Ireland), Ingredion Inc. (Bridgewater, NJ) and the Department for Employment and Learning.

The author contributions are as follows: B. E. C. conducted the laboratory analysis; B. E. C. and E. M. M. were involved in the statistical analysis; and B. E. C., P. J. A., M. M. S., P. J. M., M. B. E. L., J. J. S. and E. M. M. were involved in data interpretation. All the authors read and approved the final version of the manuscript.

The authors declare that there are no conflicts of interest.

\section{References}

1. Dawson-Hughes B, Harris SS, Krall EA, et al. (1997) Effect of calcium and vitamin D supplementation on bone density in men and women 65 years of age or older. $N$ Engl J Med 337, 670-676.

2. Tang BM, Eslick GD, Nowson C, et al. (2007) Use of calcium or calcium in combination with vitamin D supplementation to prevent fractures and bone loss in people aged 50 years and older: a meta-analysis. Lancet 370, 657-666.
3. Elwood PC, Pickering JE, Fehily AM, et al. (2004) Milk drinking, ischaemic heart disease and ischaemic stroke I. Evidence from the Caerphilly cohort. Eur J Clin Nutr 58, $711-717$.

4. Soedamah-Muthu SS, Ding EL, Al-Delaimy WK, et al. (2011) Milk and dairy consumption and incidence of cardiovascular diseases and all-cause mortality: dose-response meta-analysis of prospective cohort studies. Am J Clin Nutr 93, 158-171.

5. Lorenzen JK \& Astrup A (2011) Dairy calcium intake modifies responsiveness of fat metabolism and blood lipids to a highfat diet. Br J Nutr 105, 1823-1831.

6. Soerensen KV, Thorning TK, Astrup A, et al. (2014) Effect of dairy calcium from cheese and milk on fecal fat excretion, blood lipids, and appetite in young men. Am J Clin Nutr 99, 984-991.

7. Reid IR, Mason B, Horne A, et al. (2002) Effects of calcium supplementation on serum lipid concentrations in normal older women: a randomized controlled trial. Am J Med 112, 343-347.

8. Chai W, Cooney RV, Franke AA, et al. (2013) Effects of calcium and vitamin D supplementation on blood pressure and serum lipids and carotenoids: a randomized, doubleblind, placebo-controlled, clinical trial. Ann Epidemiol 23, $564-570$

9. Major GC, Alarie F, Doré J, et al. (2007) Supplementation with calcium + vitamin D enhances the beneficial effect of weight loss on plasma lipid and lipoprotein concentrations. Am J Clin Nutr 85, 54-59.

10. Schnatz PF, Jiang X, Vila-Wright S, et al. (2014) Calcium/ vitamin D supplementation, serum 25-hydroxyvitamin D concentrations, and cholesterol profiles in the Women's Health Initiative calcium/vitamin D randomized trial. Menopause 21, 823-833.

11. Rajpathak SN, Xue X, Wassertheil-Smoller S, et al. (2010) Effect of $5 \mathrm{y}$ of calcium plus vitamin D supplementation on change in circulating lipids: results from the Women's Health Initiative. Am J Clin Nutr 91, 894-899.

12. Reid IR, Ames R, Mason B, et al. (2010) Effects of calcium supplementation on lipids, blood pressure, and body composition in healthy older men: a randomized controlled trial. Am J Clin Nutr 91, 131-139.

13. Li S, Na L, Li Y, et al. (2013) Long-term calcium supplementation may have adverse effects on serum cholesterol and carotid intima-media thickness in postmenopausal women: a double-blind, randomized, placebo-controlled trial. Am J Clin Nutr 98, 1353-1359.

14. van Mierlo LA, Arends LR, Streppel MT, et al. (2006) Blood pressure response to calcium supplementation: a metaanalysis of randomized controlled trials. J Hum Hypertens 20, 571-580.

15. Shapses SA, Heshka S \& Heymsfield SB (2004) Effect of calcium supplementation on weight and fat loss in women. J Clin Endocrinol Metab 89, 632-637.

16. Manios Y, Moschonis G, Koutsikas K, et al. (2009) Changes in body composition following a dietary and lifestyle intervention trial: the postmenopausal health study. Maturitas $\mathbf{6 2}$, 58-65.

17. Grey A, Gamble G, Ames R, et al. (2006) Calcium supplementation does not affect CRP levels in postmenopausal women - a randomized controlled trial. Osteoporos Int 17, 1141-1145.

18. Phuwamongkolwiwat $\mathrm{P}$, Suzuki $\mathrm{T}$, Hira $\mathrm{T}$, et al. (2014) Fructooligosaccharide augments benefits of quercetin-3-O- $\beta$ glucoside on insulin sensitivity and plasma total cholesterol with promotion of flavonoid absorption in sucrose-fed rats. Eur J Nutr 53, 457-468. 
19. Coxam V (2007) Current data with inulin-type fructans and calcium, targeting bone health in adults. J Nutr 137, 2527S-2533S.

20. Morohashi T, Sano T, Ohta A, et al. (1998) True calcium absorption in the intestine is enhanced by fructooligosaccharide feeding in rats. J Nutr 128, 1815-1818.

21. Pereira DI \& Gibson GR (2002) Effects of consumption of probiotics and prebiotics on serum lipid levels in humans. Crit Rev Biochem Mol Biol 37, 259-281.

22. van den Heuvel EG, Muys T, van Dokkum W, et al. (1999) Oligofructose stimulates calcium absorption in adolescents. Am J Clin Nutr 69, 544-548.

23. Coudray C, Bellanger J, Castiglia-Delavaud C, et al. (1997) Effect of soluble or partly soluble dietary fibres supplementation on absorption and balance of calcium, magnesium, iron and zinc in healthy young men. Eur J Clin Nutr 51, 375-380.

24. Tahiri M, Tressol JC, Arnaud J, et al. (2003) Effect of shortchain fructooligosaccharides on intestinal calcium absorption and calcium status in postmenopausal women: a stableisotope study. Am J Clin Nutr 77, 449-457.

25. Slevin MM, Allsopp PJ, Magee PJ, et al. (2014) Supplementation with calcium and short-chain fructo-oligosaccharides affects markers of bone turnover but not bone mineral density in postmenopausal women. J Nutr 144, 297-304.

26. Williams CM \& Jackson KG (2002) Inulin and oligofructose: effects on lipid metabolism from human studies. Br J Nutr $\mathbf{8 7}$, Suppl. 2, S261-S264.

27. Bolland MJ, Avenell A, Baron JA, et al. (2010) Effect of calcium supplements on risk of myocardial infarction and cardiovascular events: meta-analysis. BMJ 341, c3691.

28. Bolland MJ, Grey A, Avenell A, et al. (2011) Calcium supplements with or without vitamin D and risk of cardiovascular events: reanalysis of the Women's Health Initiative limited access dataset and meta-analysis. BMJ 342, d2040.

29. Lewis JR, Radavelli-Bagatini S, Rejnmark L, et al. (2015) The effects of calcium supplementation on verified coronary heart disease hospitalization and death in postmenopausal women: a collaborative meta-analysis of randomized controlled trials. J Bone Miner Res 30, 165-175.

30. Samelson EJ, Booth SJ, Fox CS, et al. (2012) Calcium intake is not associated with increased coronary artery calcification: the Framingham Study. Am J Clin Nutr 96, 1274-1280.

31. Lewis JR, Zhu K, Thompson PL, et al. (2014) The effects of 3 years of calcium supplementation on common carotid artery intimal medial thickness and carotid atherosclerosis in older women: an ancillary study of the CAIFOS randomized controlled trial. J Bone Miner Res 29, 534-541.

32. Holland B, Welch AA, Unwin ID, et al. (1991) McCance and Widdowson's the Composition of Foods, 5th ed. Cambridge: The Royal Society of Chemistry.

33. Collins A (2006) Development and validation of methods for the measurement of micronutrient intakes relevant to bone health. PhD Thesis, National University of Ireland, Cork.

34. Heikkinen AM, Tuppurainen MT, Niskanen L, et al. (1997) Long-term vitamin $\mathrm{D}_{3}$ supplementation may have adverse effects on serum lipids during postmenopausal hormone replacement therapy. Eur J Endocrinol 137, 495-502.

35. Yacowitz H, Fleischman AI \& Bierenbaum ML (1965) Effects of oral calcium on serum lipids in man. BMJ 1, 1352-1354.

36. Reid IR (2004) Effects of calcium supplementation on circulating lipids: potential pharmacoeconomic implications. Drugs Aging 21, 7-17.

37. Ditscheid B, Keller S \& Jahreis G (2005) Cholesterol metabolism is affected by calcium phosphate supplementation in humans. J Nutr 135, 1678-1682.

38. Denke MA, Fox MM \& Schulte MC (1993) Short-term dietary calcium fortification increases fecal saturated fat content and reduces serum lipids in men. J Nutr 123, 1047-1053.

39. Johnson NE, Smith EL \& Freudenheim JL (1985) Effects on blood pressure of calcium supplementation of women. Am J Clin Nutr 42, 12-17.

40. Griffith LE, Guyatt GH, Cook RJ, et al. (1999) The influence of dietary and nondietary calcium supplementation on blood pressure: an updated metaanalysis of randomized controlled trials. Am J Hypertens 12, 84-92.

41. Huang L, Xue J, He Y, et al. (2011) Dietary calcium but not elemental calcium from supplements is associated with body composition and obesity in Chinese women. PLOS ONE 6, e27703.

42. Caan B, Neuhouser M, Aragaki A, et al. (2007) Calcium plus vitamin D supplementation and the risk of postmenopausal weight gain. Arch Intern Med 167, 893-902.

43. Hart PH, Vitti GF, Burgess DR, et al. (1989) Potential antiinflammatory effects of interleukin 4: suppression of human monocyte tumor necrosis factor alpha, interleukin 1, and prostaglandin E2. Proc Natl Acad Sci U S A 86, 3803-3807.

44. Gannagé-Yared MH, Azoury M, Mansour I, et al. (2003) Effects of a short-term calcium and vitamin D treatment on serum cytokines, bone markers, insulin and lipid concentrations in healthy post-menopausal women. J Endocrinol Invest 26, 748-753.

45. Wang L, Manson JE, Song Y, et al. (2010) Systematic review: vitamin $\mathrm{D}$ and calcium supplementation in prevention of cardiovascular events. Ann Intern Med 152, 315-323.

46. Paik JM, Curhan GC, Sun Q, et al. (2014) Calcium supplement intake and risk of cardiovascular disease in women. Osteoporos Int 25, 2047-2056.

47. Lewis JR, Calver J, Zhu K, et al. (2011) Calcium supplementation and the risks of atherosclerotic vascular disease in older women: results of a 5-year RCT and a 4.5-year follow-up. J Bone Miner Res 26, 35-41.

48. Colditz GA, Martin P, Stampfer MJ, et al. (1986) Validation of questionnaire information on risk factors and disease outcomes in a prospective cohort study of women. Am J Epidemiol 123, 894-900.

49. Lewis JR, Zhu K \& Prince RL (2012) Adverse events from calcium supplementation: relationship to errors in myocardial infarction self-reporting in randomized controlled trials of calcium supplementation. J Bone Miner Res 27, 719-722. 